\title{
Clinico-radiological correlation of nutcracker syndrome: a single centre experience
}

\author{
Aysel Taktak, M.D. ${ }^{a}$, Tulin Hakan Demirkan, M.D. ${ }^{b}$, Banu Acar, Assoc. Prof. ${ }^{a}$, Gökçe Gür, M.D. ${ }^{a}$, \\ Adem Köksoy, M.D. ${ }^{a}$, Nermin Uncu, M.D. ${ }^{a}$, Fatma Ş. Çaycl, Assoc. Prof ${ }^{a}$ and Nilgün Çakar Assoc. Prof ${ }^{a}$
}

\section{ABSTRACT}

The term nutcracker syndrome (NS) refers to the compression of left renal vein between the aorta and the superior mesenteric artery (SMA) causing renal venous hypertension. The symptoms vary from asymptomatic hematuria to severe pelvic congestion. The purpose of this study is to evaluate the clinical characteristics of patients with NS and the correlation between clinical and laboratory findings with Doppler sonographic measurements. Sixty-three patients were evaluated (19 boys and 44 girls) since January 2004 to January 2014. The mean age of the patients was $12.21 \pm 3.21$ years (range 7-17). Hematuria and proteinuria disappeared during the follow up of $9 / 63$ patients. These nine patients showed statistically significant difference in upright SMA angles $(\mathrm{p}=0.035)$.

Doppler sonographic evaluation is a non-invasive method for diagnosis NS. Upright SMA angle measurement is more efficient than supine SMA angle measurement on clinicoradiological correlation.

Key words: Renal Nutcracker syndrome, hematuria, proteinuria, child.

http:/ /dx.doi.org/10.5546/aap.2017.eng.165

To cite: Taktak A, Hakan Demirkan T, Acar B, et al. Clinico-radiological correlation of nutcracker syndrome: a single centre experience. Arch Argent Pediatr 2017;115(2):165-168. a. Department of Pediatric Nephrology and Rheumatology, Ankara Child Health, Hematology, Oncology Training and Research Hospital, Ankara, Turkey

b. Department of Radiology, Ankara Child Health, Hematology, Oncology Training and Research Hospital, Ankara, Turkey.

E-mail address: Aysel Taktak, M.D.: aysel.taktak@gmail.com

Funding: None.

Conflict of interest: None.

Received: 6-15-2016

Accepted: 10-17-2016

\section{INTRODUCTION}

Nutcracker syndrome (NS) is characterized by compression of the left renal vein (LRV) between the aorta and superior mesenteric artery (SMA) which results in elevation of pressure in the LRV and development of collateral veins/varices. ${ }^{1}$ Hematuria which varies from microhematuria to gross hematuria is the most frequent symptom attributed to rupture of thin- walled varices into the collecting system. ${ }^{2}$ Orthostatic proteinuria is also reported at NS although the exact mechanism is not known; increased hemodynamic response and subclinical immune injury are the suspected mechanisms. ${ }^{3}$ Imaging modalities such as ultrasound, computed tomography (CT), CT angiography, magnetic resonance (MR), MR angiography, Doppler sonography is required to diagnose NS although selective left renal venography is the most accurate method for diagnosing this condition. ${ }^{4,5}$ Conservative treatment is adequate for mild symptoms; surgical intervention is indicated for severe cases. ${ }^{6}$ Treatment with angiotensin converting enzyme (ACE) inhibitor is controversial however it is recommended for cases of severe and prolonged orthostatic proteinuria. ${ }^{7}$ The purpose of this study is to describe the clinical characteristics of patients with NS and the correlation between clinical and laboratory findings with Doppler sonographic measurements.

\section{Patients and methods}

Retrospective review of medical records of 63 patients followed by Pediatric Nephrology Department between January 2004 and January 2014. The following parameters were recorded; age, sex, initial symptoms, the presence of hematuria, proteinuria, renal function tests and body mass index (BMI). Patients who had systemic and/or renal causes of hematuria and proteinuria along with NS were excluded. Hematuria was defined as the presence of at least 5 red blood cells per high-power microscopic field in a centrifuged urine sample. Proteinuria was defined as $4-40 \mathrm{mg} / \mathrm{m}^{2} / \mathrm{h}$ in a 24 -hours urine collection sample. Orthostatic proteinuria was 
defined as presence of greater amounts of protein in diurnal urine than nocturnal urine. At the time of diagnosis and at last visit all patients BMIs' were calculated as weight/ stature squared (in kilograms per square meter).

Patients were diagnosed with Doppler sonography. After having fasted for 8 hours the patients were examined with 3-5 MHz convex transducers and an aplio scanner (Toshiba Medical System Co, Ltd, Tokyo, Japan). The mesenteric angle, LRV diameter and peak velocity (PV) were recorded both supine and upright positions. The antero-posterior (AP) diameter and PV were measured at both proximal and distal portion of LRV by the same experienced radiologist. None of the patients showed severe clinical or laboratory findings. Therefore conventional selective left renal venography, CT, $\mathrm{CT}$ angiography, MR and MR angiography were not performed.

Statistical analyses were performed using the SPSS software 21.0. Measurement data were reported as means \pm standard deviation. Chisquare statistics were used for the comparisons of categorical variables between independent groups. Mann-Whitney U test was used for the comparisons between two independent groups, and Wilcoxon signed-rank test was used for the dependent groups. P-values $<0.05$ were considered to indicate high statistical significance.

\section{RESULTS}

Sixty-three patients were evaluated in this study (19 boys and 44 girls). The mean age of the patients was $12.21 \pm 3.21$ years (range 7-17). The patients were mainly diagnosed with NS while being investigated for chronic flank/ abdominal pain or during the routine out-patient visits.

The mean proteinuria level was $9.1 \pm 5.5 \mathrm{mg} /$ dl. None of our patients had macroscopic hematuria or nephrotic range proteinuria.

All patients were diagnosed with Doppler sonography. Patients with narrow SMA angle in the supine position tent to have non-nephrotic proteinuria $(\mathrm{p}=0.02)$ and with narrow SMA angle in the upright position tent to have orthostatic proteinuria $(p=0.02)$.

The demographic features, clinical and laboratory results and Doppler sonographic measurements were shown at Table 1.

Hematuria and proteinuria disappeared 9 of 63 patients during the follow up. Doppler sonographic measurements were repeated in these patients. The SMA angles in the supine and upright positions after resolution of clinical symptoms were $26.25 \pm 8.56$ and $18.62 \pm 2.61$ degrees respectively. Statistically significant difference was not determined in these patients in supine SMA angles $(p=0.43)$, however there was statistical difference in upright SMA angles $(\mathrm{p}=0.035)$.

TABLE 1. The demographic features, laboratory results and Doppler sonographic measurements $(n=63)$

\begin{tabular}{|c|c|c|c|}
\hline$\underline{\text { Parameter }}$ & & Value & \\
\hline Mean age (year) & $12 \pm 3.21$ & & \\
\hline Sex & $\begin{array}{l}\text { Male } \\
\text { Female }\end{array}$ & $\begin{array}{l}\mathrm{n}=19 \\
\mathrm{n}=44\end{array}$ & $\begin{array}{l}30.1 \% \\
69.9 \%\end{array}$ \\
\hline Mean BMI & & $16.83 \mathrm{~kg} / \mathrm{m}^{2}$ (range $\left.13-22\right)$ & \\
\hline Clinical features & $\begin{array}{l}\text { Abdominal pain } \\
\text { Flank pain } \\
\text { Asymptomatic }\end{array}$ & $\begin{array}{l}\mathrm{n}=34 \\
\mathrm{n}=19 \\
\mathrm{n}=10\end{array}$ & $\begin{array}{l}53.9 \% \\
30.1 \% \\
16 \%\end{array}$ \\
\hline Microscopic hematuria & $\mathrm{n}=19$ & $30.2 \%$ & \\
\hline Proteinuria & $\mathrm{n}=44$ & $69.8 \%$ & \\
\hline Orthostatic proteinuria & $\mathrm{n}=31$ & $49.2 \%$ & \\
\hline SMA angle & $\begin{array}{l}\text { Supine } \\
\text { Upright }\end{array}$ & $\begin{array}{l}25.46 \pm 8.15 \\
15.93 \pm 4.10\end{array}$ & \\
\hline AP diameter $(\bar{x} \pm S D)$ & $\begin{array}{l}\text { Supine } \\
\text { Upright }\end{array}$ & $\begin{array}{l}2.61 \pm 1.16 \\
3.09 \pm 1.34\end{array}$ & \\
\hline Peak velocity $(\bar{x} \pm S D)$ & $\begin{array}{l}\text { Supine } \\
\text { Upright }\end{array}$ & $\begin{array}{l}3.19 \pm 1.67 \\
3.51 \pm 2.02\end{array}$ & \\
\hline
\end{tabular}


The mean diameter ratios of the proximal and distal portions of the LRV in the supine and upright positions in these patients were $2.20 \pm 0.91$ and $3.10 \pm 1.30 \mathrm{~mm}$ respectively. There was no significant difference $(p=0.71)$. Likewise PV ratios did not show any difference $(p=0.17)$.

The mean BMI of the patients was $16.83 \mathrm{~kg} /$ $\mathrm{m}^{2}$ (range 13-22) at the time of diagnosis. These nine patients' mean BMI was 17.6 \pm 2 at last visit. There was not statistically significant difference $(\mathrm{p}=0.291)$.

ACE inhibitor was initiated in three patients in with severe non-nephrotic proteinuria, patients' 24-hour urine protein excretion were $31 \mathrm{mg} / \mathrm{m}^{2} / \mathrm{h}, 19 \mathrm{mg} / \mathrm{m}^{2} / \mathrm{h}$ and $19.7 \mathrm{mg} / \mathrm{m}^{2} / \mathrm{h}$ respectively and all patients were treated with enalapril at the dose of $5 \mathrm{mg} /$ day, at the end of three months proteinuria improved to $18 \mathrm{mg} /$ $\mathrm{m}^{2} / \mathrm{h}, 11 \mathrm{mg} / \mathrm{m}^{2} / \mathrm{h}$ and $10 \mathrm{mg} / \mathrm{m}^{2} / \mathrm{h}$ respectively. This difference was not found statistically significant, due to the insufficient sample number.

\section{DISCUSSION}

Clinical symptoms and laboratory findings of NS are highly variable, and also the absence of consensus on diagnostic criteria makes the diagnosis difficult. ${ }^{8,9}$ Isolated hematuria was reported $33.3 \%$ in children with NS and microscopic hematuria is four times more common than macroscopic hematuria. ${ }^{8}$ Non nephrotic proteinuria and orthostatic proteinuria are also common symptoms of NS. The exact mechanism of orthostatic proteinuria is not well understood yet however it is attributed to renal hemodynamic changes and elevated levels of norepinephrine and angiotensin II. ${ }^{10}$

Imaging modalities such as selective left renal venography, ultrasound, computed tomography (CT), CT angiography, magnetic resonance (MR), MR angiography, and Doppler sonography can be used for diagnostic purposes although Doppler sonography is the first imaging modality with suspected NS which has a sensitivity of $78 \%$ and specificity of $100 \% .{ }^{11}$ The diagnostic measurements of NS are described by Zhang et al. According to this study, the flow velocity of stenosis of the LRV in the supine position accelerates and this acceleration became more obvious when patient has stood for $15 \mathrm{~min}$, the inner diameter ratio between the renal hilum and stenosis of LRV in the supine and upright position was $>3$ and $>5$ respectively. ${ }^{12}$ Measurement of SMA angle is a very important criterion for the diagnosis of NS as well. Fitoz et al. described the changes of SMA angle in supine and upright positions at NS, according to this study the SMA angle in supine and upright positions were $<41^{\circ}$ and $<21^{\circ}$ respectively. ${ }^{5}$

Several studies have demonstrated that during the developmental period especially BMI increasing might cause spontaneous resolution. ${ }^{4}$ However, in our series we did not show any influence of BMI on the resolution of hematuria and proteinuria in nine patients. The only statistical significant difference in these patients, whose hematuria and proteinuria resolved, was in upright SMA angles.

There is not enough evidence based trials about using angiotensin converting enzyme (ACE) inhibitors in NS. In an experimental model of partial renal vein obstruction, the glomerular plasma flow rate reduction increased transcapillary hydraulic pressure differences and efferent arteriolar resistance marked increase in urinary protein excretion have been shown; the infusion of angiotensin II antagonist reduced the protein excretion. ${ }^{13} \mathrm{Ha}$ and Lee have reported a 14-year old girl with orthostatic proteinuria due to NS, which recovered after ACE inhibition, in this case ACE inhibition, is used because of moderate mesengial hypercellularity that might be related to NS. ${ }^{7}$ ACE inhibition is suggested for cases with severe and prolonged proteinuria which may have abnormal renal pathology. However further follow up of long term clinical results; dose and duration adjustment is needed about using ACE inhibitors in NS. Our patients using ACE inhibitors showed partial resolution of proteinuria.

In conclusion NS should be considered in differential diagnosis of hematuria, proteinuria along with orthostatic proteinuria before performing renal biopsy. Doppler sonographic evaluation is a favorable non-invasive method for diagnosis of this condition. It might be concluded that upright SMA angle measurement is more efficient than supine SMA angle measurement on clinico-radiological correlation.

\section{REFERENCES}

1. DeSchepper A. Nutcracker phenomenon of the renal vein causing left renal vein pathology. J Belg Radiol 1972;55: 507-11.

2. Beinart C, Sniderman KW, Saddekni S, Weiner M, et al. Left renal vein hypertension: a cause of occult hematuria. Radiology 1982;145(3):647-50.

3. Ekim M,OzçakarZB, FitozS,SoygürT, etal. The "nutcracker phenomenon" with orthostatic proteinuria: case reports. Clin Nephrol 2006;65(4):280-3.

4. Shin JI, Park JM, Lee SM, Shin YH, et al. Factors affecting 
spontaneous resolution of hematuria in childhood nutcracker syndrome. Pediatr Nephrol 2005;20(5):609-13.

5. Fitoz S, Ekim M, Özçakar ZB, Elhan AH, et al. Nutcracker syndrome in children: The role of upright position examination and superior mesenteric artery angle measurement in the diagnosis. $J$ Ultrasound Med 2007;26(5):573-80.

6. Kurklinsky AK, Rooke TW. Nutcracker phenomenon and nutcracker syndrome. Mayo Clin Proc 2010;85(6):552-9.

7. Ha TS, Lee EJ. ACE inhibition can improve orthostatic proteinuria associated with nutcracker syndrome. Pediatr Nephrol 2006;21(11):1765-8.

8. Shin JI, Park JM, Lee JS, Kim MJ. Effect of renal Doppler ultrasound on the detection of nutcracker syndrome in children with hematuria. Eur J Pediatr 2007;166(5):399-404.

9. Rogers A, Beech A, Braithwaite B. Transperitoneal laparoscopic left gonadal vein ligation can be the right treatment option for pelvic congestion symptoms secondry to nutcracker syndrome. Vascular 2007;15(4):238-40.

10. Park SJ, Lim JW, Cho BS, Yoon TY, et al. Nutcracker syndrome in children with orthostatic proteinuria: Diagnosis on the basis of Doppler sonography. JUltrasound Med 2002;21(1):39-45.

11. Mazzoni MB, Kottanatu L, Simonetti GD, Ragazzi M, et al. Renal vein obstruction and orthostatic proteinuria: a review. Nephrol Dial Transplant 2011;26(2):562-5.

12. Zhang H, Li M, Jin W, San P, et al. The left renal entrapment syndrome: Diagnosis and treatment. Ann Vasc Surg 2007;21(2):198-203.

13. Yoshioka T, Mitarai T, Kon V, Deen WM, et al. Role of angiotensin II in an overt functional proteinuria. Kidney Int 1986;30(4):538-45. 